\title{
Plasma-electrochemical synthesis of europium doped cerium oxide nanoparticles
}

\author{
Liangliang Lin $(\bowtie))^{1}$, Xintong $\mathrm{Ma}^{2}$, Sirui Li $(\bowtie)^{2}$, Marly Wouters ${ }^{2}$, Volker Hessel ${ }^{3}$ \\ 1 School of Chemical and Material Engineering, Jiangnan University, Wuxi 214122, China \\ 2 Micro Flow Chemistry and Process Technology, Chemical Engineering and Chemistry Department, Eindhoven University of Technology, 5600 MB \\ Eindhoven, the Netherlands \\ 3 School of Chemical Engineering, The University of Adelaide, South Australia 5005, Australia
}

C The Author(s) 2019. This article is published with open access at link.springer.com and journal.hep.com.cn 2019

\begin{abstract}
In the present study, a plasma-electrochemical method was demonstrated for the synthesis of europium doped ceria nanoparticles. $\mathrm{Ce}\left(\mathrm{NO}_{3}\right)_{3} \cdot 6 \mathrm{H}_{2} \mathrm{O}$ and $\mathrm{Eu}\left(\mathrm{NO}_{3}\right)_{3} \cdot 5 \mathrm{H}_{2} \mathrm{O}$ were used as the starting materials and being dissolved in the distilled water as the electrolyte solution. The plasma-liquid interaction process was in-situ investigated by an optical emission spectroscopy, and the obtained products were characterized by complementary analytical methods. Results showed that crystalline cubic $\mathrm{CeO}_{2}: \mathrm{Eu}^{3+}$ nanoparticles were successfully obtained, with a particle size in the range from 30 to $60 \mathrm{~nm}$. The crystal structure didn't change during the calcination at a temperature from $400^{\circ} \mathrm{C}$ to $1000^{\circ} \mathrm{C}$, with the average crystallite size being estimated to be $52 \mathrm{~nm}$ at $1000^{\circ} \mathrm{C}$. $\mathrm{Eu}^{3+}$ ions were shown to be effectively and uniformly doped into the $\mathrm{CeO}_{2}$ lattices. As a result, the obtained nanophosphors emit apparent red color under the UV irradiation, which can be easily observed by naked eye. The photoluminescence spectrum further proves the downshift behavior of the obtained products, where characteristic ${ }^{5} \mathrm{D}_{0} \rightarrow{ }^{7} \mathrm{~F}_{1,2,3}$ transitions of $\mathrm{Eu}^{3+}$ ions had been detected. Due to the simple, flexible and environmental friendly process, this plasma-electrochemical method should have great potential for the synthesis of a series of nanophosphors, especially for bio-application purpose.
\end{abstract}

Keywords plasma-electrochemical method, europium doped ceria, rare earth nanoparticles, photoluminescence

Received August 1, 2018; accepted December 25, 2018

E-mails: s.li1@tue.nl, linliangliang@jiangnan.edu.cn

\section{Introduction}

As the most abundant rare earth metal which comprises about $0.0046 \%$ by weight in the Earth's crust, cerium (Ce) and cerium-based compounds have historically gained great interests from different fields [1]. Among them $\mathrm{CeO}_{2}$ has received much attention due to the low reduction potential and coexistence of $\mathrm{Ce}^{3+} / \mathrm{Ce}^{4+}$ on its surfaces. The interchangeability of the valence states $(4+$ and $3+)$ of the cerium ions leads to oxygen vacancies within the $\mathrm{CeO}_{2}$. In such a case, electrons are regarded as small polarons, and the motion of the electrons is imagined as a thermally mediated hopping mechanism [2]. This property makes $\mathrm{CeO}_{2}$ an attractive material for oxide ion conductors, and remarkable applications ranging from catalysts, fuel cells, host material to electrochemical devices, antioxidants and gas sensors have been explored [3]. Beside the use in the aforementioned fields, the application of $\mathrm{CeO}_{2}$ nanoparticles in the life science industry has been researched over the last years. The interest in this field started in 2006 when the first in vitro cytotoxicity tests for nanoparticles concluded that ceria has a low toxic effect [4]. The redox reaction cycle between the two oxidation states of the cerium ions has a good similarity to antioxidant enzymes [5]. However, for the use in cell imaging or as light source for cancer treatment, the emission of $\mathrm{CeO}_{2}$ itself is very weak. Suitable doping activators in $\mathrm{CeO}_{2}$ matrix are needed to achieve good emission performance. Recently, europium doped cerium oxides have been considered as promising luminescent lanthanide complexes. It is wellknown that europium has a strong red emission and can be excited from ultraviolet to visible light. An optimal spectral overlap is found to exist between the charge transfer band of $\mathrm{CeO}_{2}$ and the $4 \mathrm{f}-4 \mathrm{f}$ intra configurational transitions of $\mathrm{Eu}^{3+}$ ions. The absence of electrons in the $4 \mathrm{f}$ shell makes $\mathrm{CeO}_{2}$ an ideal host material for europium. By 
doping $\mathrm{Eu}^{3+}$ ions into $\mathrm{CeO}_{2}$ host, it can encourage effective energy transfer from the $\mathrm{Ce}^{4+}-\mathrm{O}^{2-}$ host to $\mathrm{Eu}^{3+}$ ions and greatly enhance the luminescent properties [6]. Moreover, since the ionic radius of $\mathrm{Eu}^{3+}(0.1066 \mathrm{~nm})$ is close to that of $\mathrm{Ce}^{3+}(0.1143 \mathrm{~nm})$ and $\mathrm{Ce}^{4+}(0.097 \mathrm{~nm})$, it favors extensive solubility of $\mathrm{Eu}^{3+}$ within the ceria lattice [7].

Owing to the low dimensionality and large surface area, nanoparticles usually exhibit unique properties that differ considerably from bulk materials. The decrease of the $\mathrm{CeO}_{2}$ size can prompt the formation of oxygen vacancies, leading to an improved electron mobility. Once reduced to the nm-level, these oxygen vacancies can alter the electronic and valence arrangement. In this case, the substitution of $\mathrm{Ce}^{4+} / \mathrm{Ce}^{3+}$ by $\mathrm{Eu}^{3+}$ will greatly enhance the emission characteristics of $\mathrm{CeO}_{2}$ particles, since it is more convenient for energy transfer between $\mathrm{Eu}^{3+}$ and the redox pair $\mathrm{Ce}^{4+}$ and $\mathrm{Ce}^{3+}$ oxidation states. Besides, nano-sized particles have the possibility to be transported through tissues and even cells. If $\mathrm{CeO}_{2}: \mathrm{Eu}^{3+}$ nanoparticles were engineered with appropriate proteins, they can be used for bio-imaging or bio-labelling purpose. This in combination with their intrinsic low toxicity, good biocompatibility, high chemical stability and excellent luminescent property further prompt their applications in the life science field.

Despite the promising perspective of $\mathrm{CeO}_{2}: \mathrm{Eu}^{3+}$ nanoparticles for bio-applications, currently it is still a challenge to prepare high purity crystalline products in a simple and environmentally friendly manner. Conventional wet chemistry methods require the usage of extra chemicals and pretreatment of the solution. Meanwhile, stabilizers or surfactants which used to limit particle growth are commonly needed. As a result, purification procedures like repeated washing and drying are need to get rid of impurities [8]. On top of that, these methods usually involve toxic chemicals, which may cause unexpected influence on biosystems or on the environment. As to solid-state reaction methods, they are almost operated at sintering temperatures as high as $1500^{\circ} \mathrm{C}-$ $1600^{\circ} \mathrm{C}$, with the grain size of the obtained powders on the order of 5-20 $\mu \mathrm{m}$. Thus, to obtain nano-sized $\mathrm{CeO}_{2}: \mathrm{Eu}^{3+}$ phosphors for bio-application uses, the powders must be repeatedly ground and milled. Due to the introduction of additional defects during the mechanical procedures, it can greatly reduce the luminescence efficiency of the products.

As a partially ionized gas consisting of electrons, ions, photons, molecules and excited species, plasma-based method can be a promising solution. Due to the existence of abundant reactive species, some thermodynamically unfavorable reactions can take place easily in plasmas under mild conditions [9]. In recent years, plasma-assisted nanofabrication has attracted considerable interests, especially plasma-based liquid electrochemical synthesis. It is well-known that liquid has a larger density than gas. The generation plasma in liquid will have additional confinements, resulting in a higher density of reactive species.
Moreover, heat can be dissipated immediately in liquid, ensuring a rather low system temperature as well as limited particle nucleation and growth rate. Therefore, the obtained nanoparticles have smaller sizes and narrower size distributions [10-12].

In the present work, a plasma-electrochemical method was introduced for the synthesis of $\mathrm{CeO}_{2}: \mathrm{Eu}^{3+}$ nanoparticles. The goal is to explore a simple and green way to prepare rare-earth element doped cerium oxide without involving any toxic chemicals and complex purification processes. Because of the high reactivity of plasma, the plasma-liquid interaction in the aqueous layer can form active radicals like $\mathrm{OH}, \mathrm{O}$ and $\mathrm{H}$ from water molecules. This can avoid the usage of extra hydrolyzing agents, stabilizers and surfactants, which also favors the application of the generated products in bio-related fields.

\section{Experimental}

In this study all experiments were carried out in a speciallydesigned plasma reactor (Fig. 1), which has been successfully used to synthesize yttrium oxides and TiN nanoparticles $[13,14]$. Detailed information of the experimental setup can be referred to the above researches. The electrolyte solution was prepared by dissolving $\mathrm{Ce}$ $\left(\mathrm{NO}_{3}\right)_{3} \cdot 6 \mathrm{H}_{2} \mathrm{O}(434.22 \mathrm{~g} / \mathrm{mol}$, Sigma Aldrich) and $\mathrm{Eu}$ $\left(\mathrm{NO}_{3}\right)_{3} \cdot 5 \mathrm{H}_{2} \mathrm{O}(428.06 \mathrm{~g} / \mathrm{mol}$, Sigma Aldrich) in demineralized $\mathrm{H}_{2} \mathrm{O}$ to obtain a total $\mathrm{Eu} / \mathrm{Ce}$ concentration of $0.05 \mathrm{~mol} / \mathrm{L}$. The ratio of europium to cerium was varied

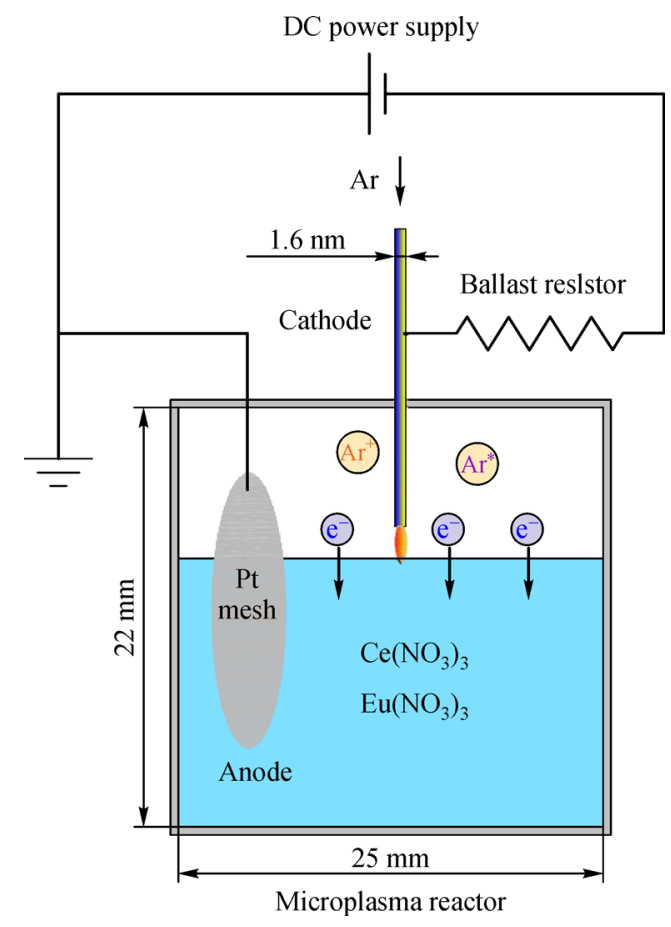

Fig. 1 The schematic diagram of the microplasma reactor used in this study 
between 0 and $10 \%$. In a typical procedure, $10 \mathrm{~mL}$ solution was filled in the quartz microplasma reactor. A capillary (I.D. $=318 \mu \mathrm{m}$, O.D. $=1.6 \mathrm{~mm}$ ) made from stainless steel was used as a cathode and being placed $1 \mathrm{~mm}$ above the liquid surface. A platinum disk was immersed in the liquid as the counter electrode. To ignite and sustain the plasma, both electrodes were connected to a negatively biased DC power supply (Matsusada Precision, Model AU-10R30), with the anode electrode being grounded. In each operation, a continuous argon flow of $100 \mathrm{sccm}$ was coupled into the capillary as the plasma gas. It was flowed into the sealed reactor for several minutes before the reaction to get rid of impurities like oxygen and nitrogen. The gas flow rate was controlled by a mass flow controller. During the reaction, no external heating was applied. Experimental values of the plasma current, voltage and power can be automatically recorded using a LabVIEW based program. After the plasma-electrochemical reactions, the solution was centrifuged for $10 \mathrm{~min}$ at $4000 / \mathrm{s}$ to obtain the products, which were then dried at $50^{\circ} \mathrm{C}$ to get solid powders. Afterwards, these powders were furtherly heat-treated at different temperatures to get the oxide product, and they were carefully scraped from the plate for complementary characterization.

The optical emission spectra were recorded using an HR2000 + ES spectrometer (Ocean Optics, Inc.). This non-intrusive technique helps to identify the existed reactive species in the complex plasma-assisted process, and gives valuable information of the excited states of the short-live radicals. The emitted light during the plasmaliquid interactions were collected by an optical fiber fixed which was fixed $20 \mathrm{~mm}$ from the electrodes axis. The energy dispersive X-ray spectroscopy (EDX) characterization was performed with a Phenom ProX (Phenom World), with a silicon drift EDX detector to examine the element distribution (Sapphire DPP-2). Transmission electron microscopy (TEM) and high-resolution TEM images were obtained using a FEI Tecnai 20 (Sphera) microscopy operated with a $200 \mathrm{kV} \mathrm{LaB6}$ filament. The X-ray diffraction patterns of the synthesized particles were obtained with a Rigaku Powder Diffractometer using $\mathrm{Cu}$ $K_{\alpha 1}$ radiation $\left(K_{\alpha}=1.54056 \AA\right)$. The scans were recorded in a $2 \theta$ step of $0.02^{\circ}$ with a dwell time of $20 \mathrm{~s}$ in each step. The Raman spectroscopy measurements were taken with a Labram confocal Raman microscope (Horiba Jobin-Yvon) with a laser diode emitting light at $632 \mathrm{~nm}$ and an 1800 lines $/ \mathrm{mm}$ grating. Si wafer was used to calibrate the Raman system by the prominent peak at the wavelength of $520.6 \mathrm{~cm}^{-1}$, followed by the measurement of solid samples on a glass substrate. The measurements were performed at laser power density of $1 \mathrm{~mW}$. The XPS measurements were carried out with a Thermo Scientific K-Alpha X-ray photoelectrons spectroscopy, equipped with a monochromatic small-spot X-ray source and a $180^{\circ}$ double focusing hemispherical analyzer with a 128-channel detector. Spectra were obtained using an aluminium anode (Al $K_{\alpha}$ $=1486.6 \mathrm{eV}$ ) operated at $72 \mathrm{~W}$ and a spot size of $400 \mu \mathrm{m}$. Survey scans were measured at a constant pass energy of $200 \mathrm{eV}$ and region scans at $50 \mathrm{eV}$. The photoluminescence measurements were performed at room temperature on a luminescence spectrometer (Perkin Elmer, Model LS-50B) using $360 \mathrm{~nm}$ wavelength as the excitation wavelength. The samples were prepared by pressing solid powders into a hole on the sample holder with a glass slide.

\section{Results and discussion}

Time-evolution images of the plasma-treated electrolyte solution are presented in Fig. 2. It is shown that the clear and colorless solution gradually turns into slightly white and semitransparent after plasma operation for $1 \mathrm{~h}$, in which white floccules are formed. This suggests chemical reactions can be induced by the plasma-assisted process, without the addition of extra chemicals. As the plasmadriven process continues, the semitransparent solution becomes increasingly turbid. One can observe that more and more white floccules were generated and deposited from the electrolyte. The solution becomes totally creamy white after approximately $4 \mathrm{~h}$.

In addition to the visual-appearance of the plasmatreated solution, we also investigated the optical emission spectra of the plasma-liquid interaction process. In this research, both the emission spectra of pure argon plasma as well as argon plasma interacting with the electrolyte solution were acquired, as shown in Fig. 3. For the pure argon case, the spectrum is merely composed of emission lines in the red/near-infrared spectral region $(680-950 \mathrm{~nm})$, which can be attributed to the argon $3 p^{5} 4 p-3 p^{5} 4 s$ transitions. By contrast, when interacting with the liquid

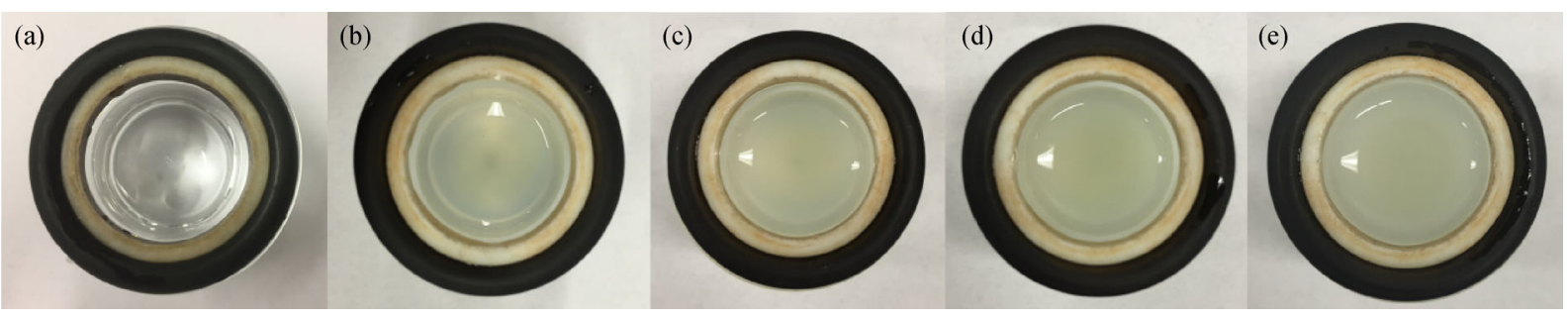

Fig. 2 The images of the electrolyte solution treated by plasma for (a) $0 \mathrm{~h}$, (b) $1 \mathrm{~h}$, (c) $2 \mathrm{~h}$, (d) $3 \mathrm{~h}$ and (e) $4 \mathrm{~h}$ 
solution, new spectral features of the neutral hydrogen line at $\lambda=656 \mathrm{~nm}\left(\mathrm{H}_{\mathrm{a}}\right)$ as well as the molecular bands of the $\mathrm{OH}$ radicals at $\lambda=310 \mathrm{~nm}$ (the $3064 \AA$ system) are observed, suggesting the splitting of $\mathrm{H}_{2} \mathrm{O}$ molecules under the plasma impact [15].

In the studied reactor configuration, the capillary tube was negatively biased with respect to the platinum electrode. Owing to the external electrical field, plasma electrons were driven toward the electrolyte surface to collide with water molecules. These energetic electrons can dissociate water molecules to generate $\mathrm{H}$ and $\mathrm{OH}$ radicals, which have been detected by the OES spectra Eq. (1). Meanwhile, metastable $\mathrm{OH}$ radicals are highly reactive. They will combine with plasma electrons to form $\mathrm{OH}^{-}$in the liquid Eq. (2). On the other hand, the equilibrium solubilities of the studied lanthanide hydroxides are rather low $\left(\sim 10^{-7} \mathrm{~g} / \mathrm{mL}\right)$. Both the europium ions and the cerium ions are easily hydrolyzed to form colloidal deposits from the electrolyte solution Eq. (3). This can be reflected by the images of the electrolyte solution under plasma treatment at different times (Fig. 2).

$$
\begin{aligned}
\mathrm{H}_{2} \mathrm{O}+\mathrm{e}^{-} & \rightarrow \mathrm{H}^{\bullet}+\mathrm{OH}^{\bullet} \\
\mathrm{OH}^{\cdot}+\mathrm{e}^{-} & \rightarrow \mathrm{OH}^{-} \\
\mathrm{Ce}^{3+}+\mathrm{Eu}^{3+}+3 \mathrm{OH}^{-} & \rightarrow\left[\mathrm{Ce}(\mathrm{OH})_{3}: \mathrm{Eu}\right] \downarrow
\end{aligned}
$$

The elemental mapping over a random area of the $\mathrm{Eu}^{3+}$ doped $\mathrm{CeO}_{2}$ samples reveals the existence of $\mathrm{Ce}, \mathrm{O}$ and $\mathrm{Eu}$ elements, without the appearance of any other impurities (Figs. 4(a-d)). Moreover, Eu shows a homogeneous distribution among the $\mathrm{Ce}$ and $\mathrm{O}$ element, suggesting it has been uniformLy incorporated into the $\mathrm{CeO}_{2}$ nanoparticles. The EDX analysis further confirms this result, where strong $\mathrm{Ce}$ and $\mathrm{O}$ as well as low intensity $\mathrm{Eu}$ signals are observed, and no extra impurities are detected (Fig. 4(e)).
Figure 5(a) shows the XRD patterns of $\mathrm{CeO}_{2}: \mathrm{Eu}^{3+}$ nanoparticles with the europium doping concentration varying from $2 \%$ to $10 \%$. In general, all the diffractions peaks locate at the same positions and well match with the cubic fluorite structure of $\mathrm{CeO}_{2}$ (JCPDS \#81-0792) [16]. No peaks of $\mathrm{Eu}, \mathrm{Eu}_{2} \mathrm{O}_{3}$ and $\mathrm{Eu}(\mathrm{OH})_{3}$ are detected, indicating that europium have been effectively entered into the $\mathrm{CeO}_{2}$ lattice. However, compared with pure $\mathrm{CeO}_{2}$, the diffraction peaks of $\mathrm{Eu}$ doped $\mathrm{CeO}_{2}$ nanoparticles shift to a larger $2 \theta$ value, which can be observed more clearly in the range from $26^{\circ}$ to $34^{\circ}$. This is attributable to the doping of emporium ions into the host matrix, where emporium ions have a larger ionic radius $(r=1.1206 \AA)$ than cerium ions $(r=1.11 \AA)$, leading to the lattice expansion [17]. The influence of the annealing temperature is also investigated (Fig. 5(b)). For powders dried at room temperature, only three broad peaks with very low intensities at $28^{\circ}, 47^{\circ}$ and $56^{\circ}$ are visible, suggesting they are poorly crystallized. In the temperature range from $400^{\circ} \mathrm{C}$ to $1000^{\circ} \mathrm{C}$, the peaks show an apparent narrowing trend, inferring an enhanced crystallite growth with the increased temperature. Meanwhile, all peaks are characteristic diffractions of the cubic fluorite structure, suggesting no structural change during the calcination process. The average crystalline size $(d)$ of the nanoparticles annealed at $1000^{\circ} \mathrm{C}$ is estimated from the highest intensity peak (111) at $28^{\circ}$ using the Scherrer formula

$$
d=\frac{K \lambda}{\beta \cos \theta}
$$

where $K$ is the shape factor, which is 0.89 for the cubic fluorite structure of ceria; $\lambda$ the wavelength of the X-rays (1.54056 $\AA$ ); $\beta$ is the line broadening at half maximum peak intensity in radians; $\theta$ is the Bragg angle [18]. It is calculated that the crystallite size is $52.2 \mathrm{~nm}$ at the studied condition.

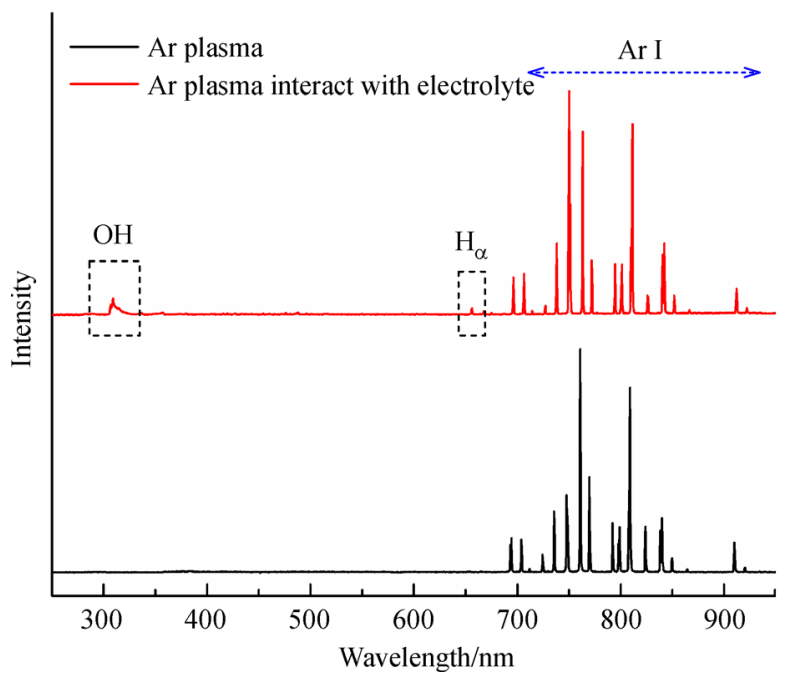

Fig. 3 Emission spectra of pure argon plasma as well as argon plasma interacting with the electrolyte solution 


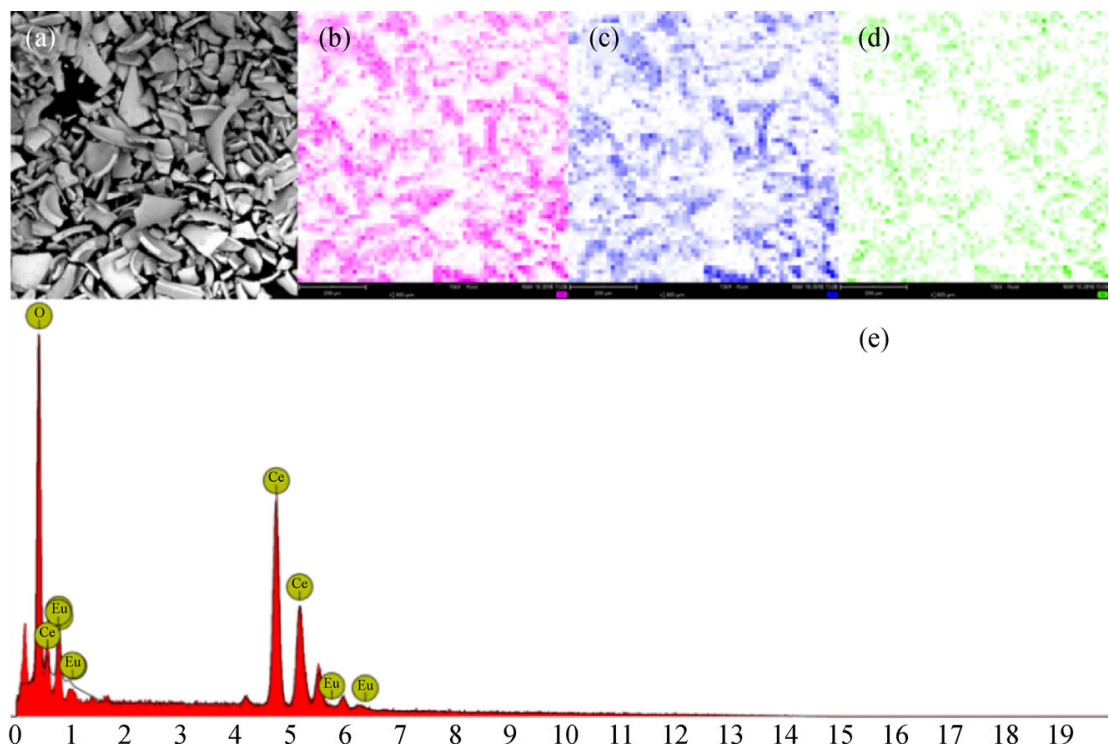

Fig. 4 (a) Element mapping area, (b) Ce, (c) O, (d) Eu and (e) EDX spectrum of the obtained samples
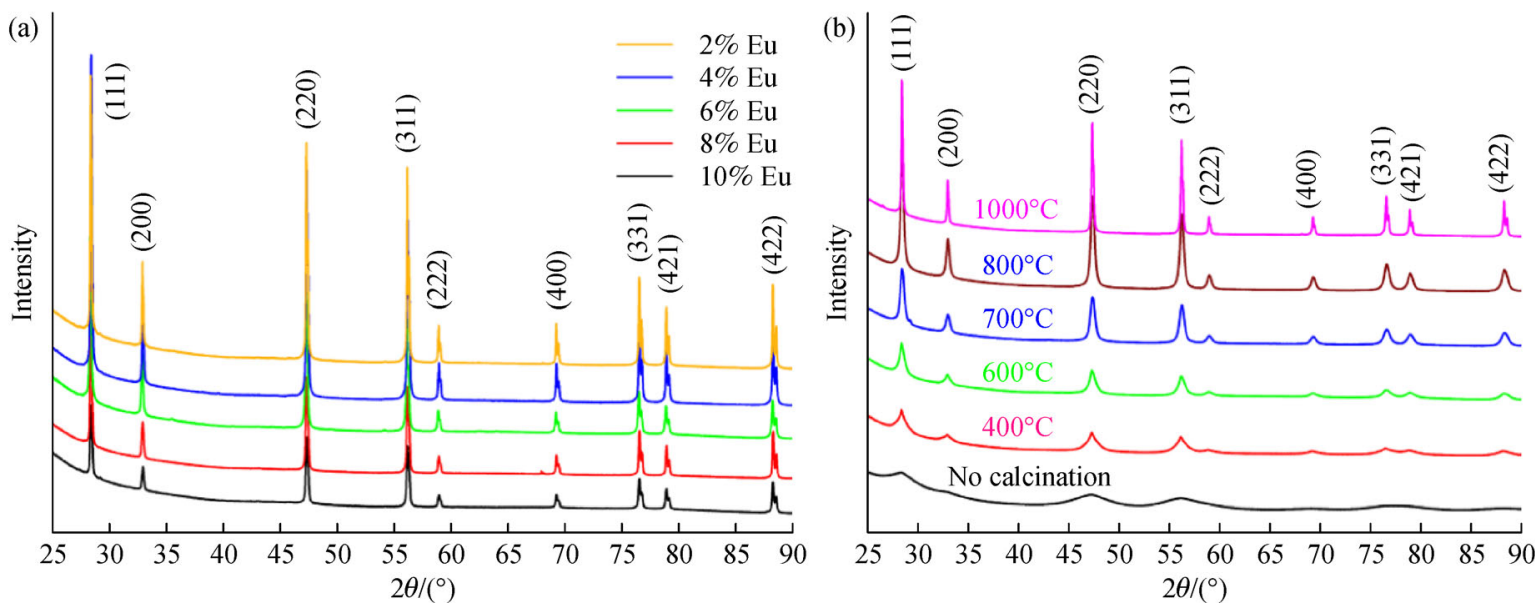

Fig. 5 (a) XRD patterns of $\mathrm{CeO}_{2}: \mathrm{Eu}^{3+}(2 \mathrm{~mol} \%-10 \mathrm{~mol} \%)$ annealed at $1000^{\circ} \mathrm{C}$; (b) $\mathrm{XRD}$ patterns of $\mathrm{CeO}_{2}: \mathrm{Eu}^{3+}$ annealed at different temperatures

Figures $6(a, b)$ show representative TEM images of the $\mathrm{CeO}_{2}: \mathrm{Eu}^{3+}$ products. Nano-sized particles of irregular shapes were observed, with measured size ranging from 30 to $60 \mathrm{~nm}$. Due to the calcination, they are partially aggregated together. It is noteworthy that this technique allows the preparation of nanoparticles within $60 \mathrm{~nm}$ at $1000^{\circ} \mathrm{C}$, which are much smaller compared with other physical or chemical methods that without stabilizers or surfactants (those are mostly larger than $100 \mathrm{~nm}$ and may reach micro-size level) $[19,20]$. Since conventional wet chemistry methods use supersaturated alkali precipitants, cerium hydroxides easily nucleate and grow to a large extent due to the vigorous hydrolyzing reactions. By contrast, in this method $\mathrm{OH}^{-}$are smoothly generated from water molecules to deposit ultra-small floccules in a mild condition, avoiding overgrowth of the deposits. The atomic-level particle structure was also examined by the high-resolution image, as shown in Fig. 6(c). Clear lattice fringes are observed, implying the crystalline nature of the synthesized particles. This was supported by the inserted FFT image as well as by the SAED image, in which diffraction rings arising from the (111), (200), (220), and (311) lattice planes are detected.

Raman analysis was performed to provide a structural fingerprint of $\mathrm{CeO}_{2}$ nanoparticles with $\mathrm{Eu}^{3+}$ doping. Figure 7 shows the raman spectra of $\mathrm{CeO}_{2}$ nanoparticles with (red one) and without (black one) $\mathrm{Eu}^{3+}$ doping. For the pure $\mathrm{CeO}_{2}$ nanoparticles, a significant band located at $465 \mathrm{~cm}^{-1}$ is observed, which is ascribed to the first order scattering of $\mathrm{CeO}_{2}$ nanoparticles $\left(\mathrm{F}_{2 \mathrm{~g}}\right.$ mode). This band is 


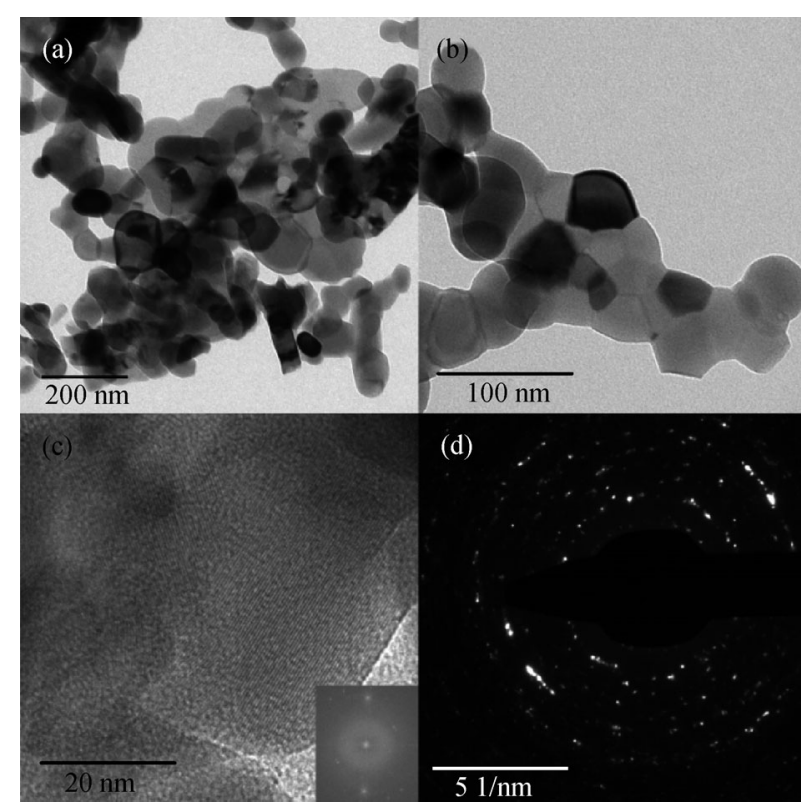

Fig. 6 (a,b) Representative TEM images, (c) HRTEM image and (d) SAED image of $10 \%$ Eu-doped $\mathrm{CeO}_{2}$ nanoparticles obtained at $1000^{\circ} \mathrm{C}$

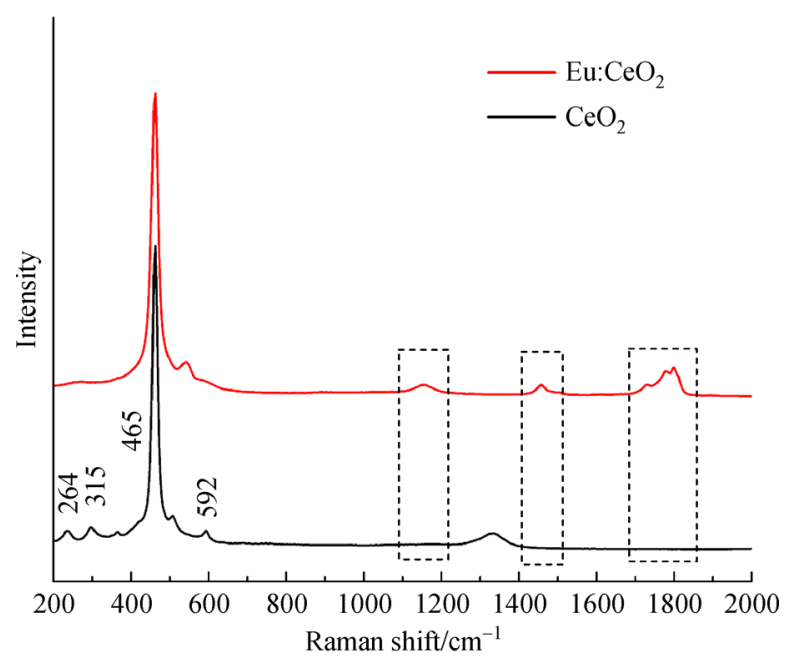

Fig. 7 Raman spectra of $\mathrm{CeO}_{2}$ nanoparticles with and without $\mathrm{Eu}^{3+}$ doping

caused by the stretching of the $\mathrm{Ce}-\mathrm{O}-\mathrm{Ce}$ symmetric vibration, where $\mathrm{Ce}$ and $\mathrm{O}$ are 8-fold and 4-fold coordinated [21]. Additionally, a number of bands ranging from 250 to $1400 \mathrm{~cm}^{-1}$ that originated from the second order scattering are also detected. These bands belong to different phonon symmetry modes. By contrast, for the $\mathrm{Eu}^{3+}$ doped $\mathrm{CeO}_{2}$ nanoparticles, several new bands emanated from 1150 to $1850 \mathrm{~cm}^{-1}$ are detected, suggesting the chemical bonds and symmetric vibration are changed. This is entirely due to the incorporation of $\mathrm{Eu}^{3+}$ into the $\mathrm{CeO}_{2}$ matrix. Same phenomenon has been reported by
Burger et al., where $\mathrm{Eu}^{3+}$ was doped into yttria by wet chemical routes with combustion and coprecipitation techniques [22]. The Raman results further confirms the successful synthesis of $\mathrm{CeO}_{2}$ nanoparticles as well as the doping of $\mathrm{Eu}^{3+}$ into the $\mathrm{CeO}_{2}$ matrix by the plasmainduced technique.

To further investigate the chemical compositions and binding information of the products, XPS characterization is employed for both $\mathrm{Eu}^{3+}$ doped and undoped $\mathrm{CeO}_{2}$ nanoparticles (Fig. 8). It is clearly shown that both samples consist of $\mathrm{Ce}$ and $\mathrm{O}$. However, the peaks corresponding to $\mathrm{Eu} 4 \mathrm{~s}$ and $\mathrm{Eu} \mathrm{3d}$ are not visible in the undoped ceria spectrum but are in the doped spectrum $(\sim 400$ and $1135 \mathrm{eV})$. The result is in consistent with the EDX result, reconfirming the presence of europium in ceria. To get more details about the element states, high resolution spectra of $\mathrm{Ce} 3 \mathrm{~d}, \mathrm{Eu} 3 \mathrm{~d}$ and $\mathrm{O} 1 \mathrm{~s}$ are presented in Figs. 8(b-d). For the $\mathrm{Ce} 3 \mathrm{~d}$, the spin-orbital-splitting of the $3 \mathrm{~d}_{5 / 2}(878-898 \mathrm{eV})$ and $3 \mathrm{~d}_{3 / 2}(898-920 \mathrm{eV})$ are clearly visible. Each doublet is further split by multiple splitting, representing different $4 \mathrm{f}$ configurations in the photoemission initial and the final states. The peaks at 898 and $916.7 \mathrm{eV}$ are indexed to the $\mathrm{Ce}^{4+} 3 \mathrm{~d}_{3 / 2}$ and $\mathrm{Ce}^{4+} 3 \mathrm{~d}_{5 / 2}$ contributions, while the peaks situated at 882.8 and $901.4 \mathrm{eV}$ correspond to the binding energy of $\mathrm{Ce}^{3+} 3 \mathrm{~d}_{3 / 2}$ and $\mathrm{Ce}^{3+} 3 \mathrm{~d}_{5 / 2}$. Therefore, it demonstrates the existence of a small amount of $\mathrm{Ce}^{3+}$ at the surface, which is well-known for $\mathrm{CeO}_{2}$ nanoparticles [23]. The results are characteristic spectral features of ceria, and can be taken as evidence of the formation of $\mathrm{CeO}_{2}$ nanoparticles [24]. The $\mathrm{Eu} \mathrm{3d}$ binding at 1163 and $1134 \mathrm{eV}$ are assigned to the $\mathrm{Eu}^{3+} 3 \mathrm{~d}_{5 / 2}$ and $\mathrm{Eu}^{3+} 3 \mathrm{~d}_{3 / 2}$, respectively, indicating the formation of $\mathrm{Eu}-\mathrm{O}$ bonds from europium ions which exist in the form of trivalent ions $\left(\mathrm{Eu}^{3+}\right)$. This revealed that part of europium ions form $\mathrm{Eu}_{2} \mathrm{O}_{3}$ within the nanophosphors. Spectral decomposition of $\mathrm{O} 1 \mathrm{~s}$ bands further confirms the above findings. The most prominent peak at $529.1 \mathrm{eV}$ as well as the associated low intensity peak at $530.5 \mathrm{eV}$ are typical $\mathrm{O}-\mathrm{Ce}$ bonds that widely existed in $\mathrm{CeO}_{2}$ nanoparticles [25]. Moreover, as reported by Yuan et al., two additional peaks at 532.2 and $533.4 \mathrm{eV}$ are due to $\mathrm{O}-\mathrm{Eu}$ binding as well as the oxide impurities such as $\mathrm{O}-\mathrm{C}$ compounds or O-H species [26].

Figure 9 shows representative emission spectra of $\mathrm{CeO}_{2}$ nanoparticles without/with $4 \%$ Eu doping. In Fig. 9(a), a broad emission bands are observed at around 390 and $415 \mathrm{~nm}$ when irradiated at $300 \mathrm{~nm}$, which are characteristic spectral features of $\mathrm{CeO}_{2}$, in consistent with reference [27]. Meanwhile, the emission bands located between 340 and $500 \mathrm{~nm}$ are originated from the defect states of $\mathrm{CeO}_{2}$, such as oxygen vacancies between $\mathrm{Ce} 4 \mathrm{f}$ state to $\mathrm{O} 2 \mathrm{p}$ state [28]. As to the emission spectrum of $\mathrm{Eu}^{3+}$ doped $\mathrm{CeO}_{2}$ nanophosphors, two most intensive peaks situated at 589 and $612 \mathrm{~nm}$ are indexed to the ${ }^{5} \mathrm{D}_{0} \rightarrow{ }^{7} \mathrm{~F}_{1}$ and ${ }^{5} \mathrm{D}_{0} \rightarrow{ }^{7} \mathrm{~F}_{2}$ transition of $\mathrm{Eu}^{3+}$ ions, respectively. The ${ }^{5} \mathrm{D}_{0} \rightarrow{ }^{7} \mathrm{~F}_{1}$ transition is known as the parity-allowed magnetic dipole 

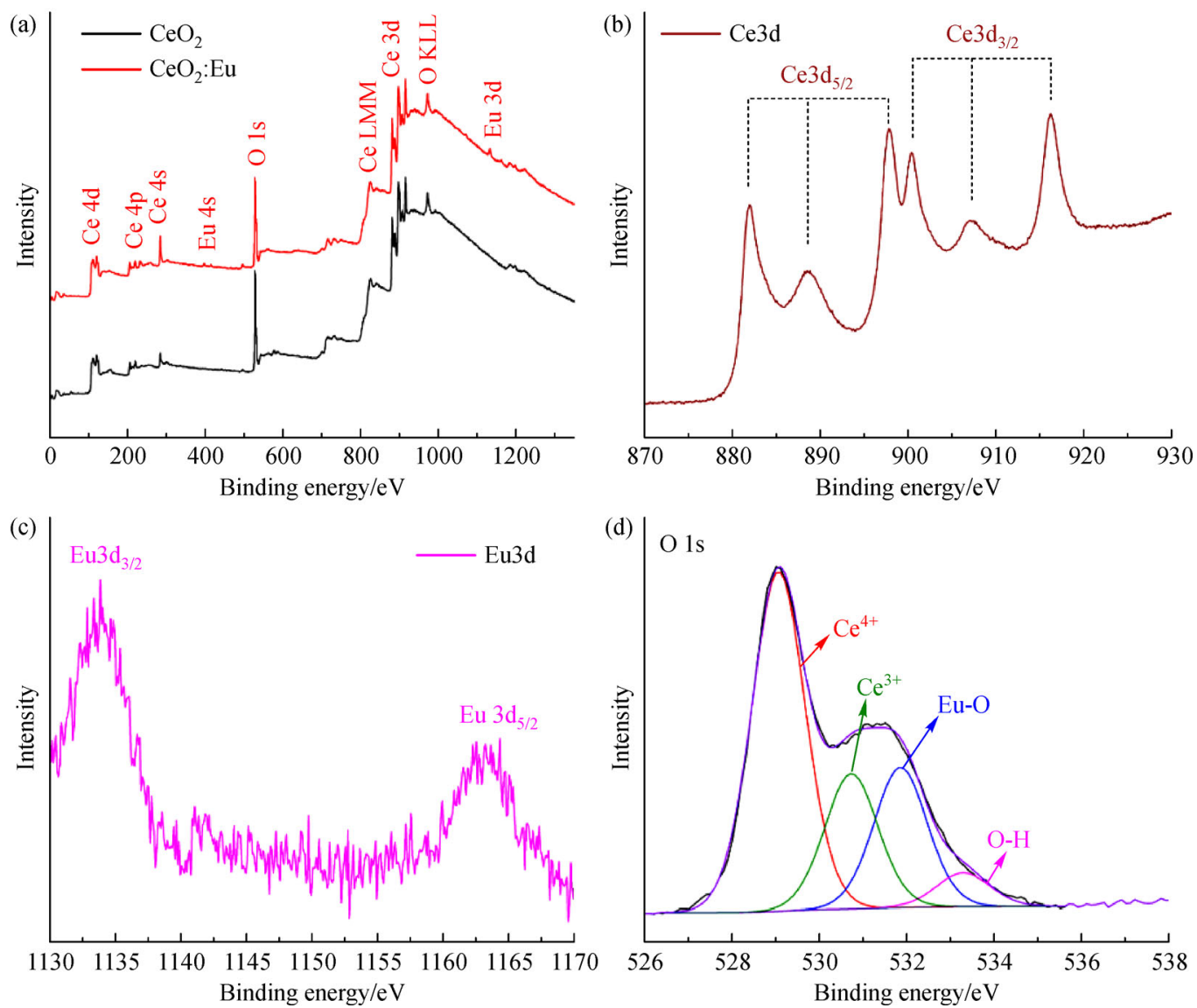

Fig. 8 (a) Full XPS spectra of $\mathrm{CeO}_{2}$ nanoparticles with and without $\mathrm{Eu}^{3+}$ doping; (b) XPS spectrum of Ce3d; (c) XPS spectrum of Eu3d; (d) XPS spectrum and the associated spectral decomposition of O1s
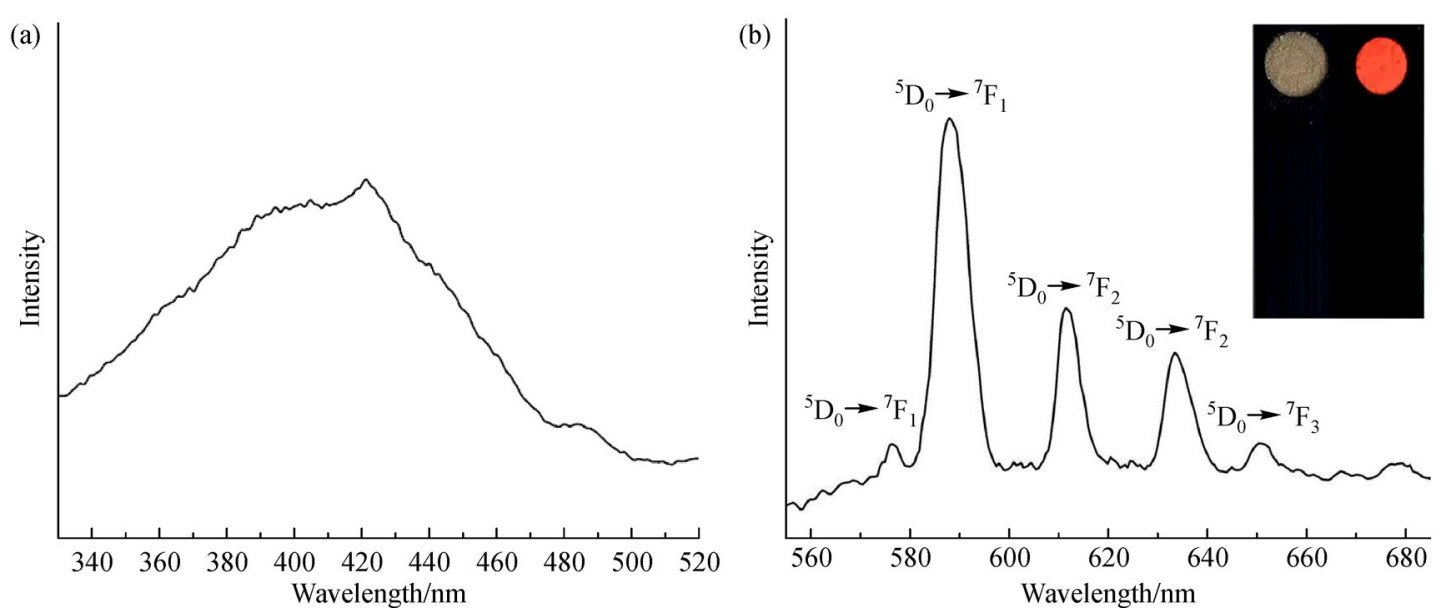

Fig. 9 Representative photoluminescent emission spectra (a) $\mathrm{CeO}_{2}$ and (b) $\mathrm{CeO}_{2}: 4 \%$ Eu under UV excitation. Inset shows a typical photograph of the obtained nanophosphors under the UV irradiation of $360 \mathrm{~nm}$

transition and is insensitive to the crystal field environment, while the ${ }^{5} \mathrm{D}_{0} \rightarrow{ }^{7} \mathrm{~F}_{2}$ transition originates from the electronic dipole transition and being hypersensitive to the local symmetry around the $\mathrm{Eu}^{3+}$ ions. According to the Judd-Ofelt theory, the incorporation of $\mathrm{Eu}^{3+}$ ions into
$\mathrm{CeO}_{2}$ host would perturb their structure. At low doping concentrations, the $\mathrm{Eu}^{3+}$ ions mainly enter into the lattice with inversion symmetry. With the increased $\mathrm{Eu}^{3+}$ doping, they can replace $\mathrm{Ce}^{4+}$ and create symmetry distortions to cause the electric dipole transitions [6]. In the present case, 
the ${ }^{5} \mathrm{D}_{0} \rightarrow{ }^{7} \mathrm{~F}_{1}$ transition is found to be higher than the $\mathrm{D}_{0} \rightarrow{ }^{7} \mathrm{~F}_{2}$ transitions, indicating that most of the $\mathrm{Eu}^{3+}$ ions go into the lattice instead of occupying the $\mathrm{Ce}^{4+}$ sites. This agrees with the study of Shi et al., where the ${ }^{5} \mathrm{D}_{0} \rightarrow{ }^{7} \mathrm{~F}_{1}$ transition is stronger than other transitions at the $4 \% \mathrm{Eu}^{3+}$ doping concentration [17]. In addition, an optical photograph of the nanophosphor under the same UV wavelength is also shown in the inset of Fig. 9(b). Apparent red fluorescent light is clearly visible from the $\mathrm{CeO}_{2}: \mathrm{Eu}^{3+}$ sample by the naked-eye, confirming their downshifting nature.

Currently a series of methods have been developed for the synthesis of europium doped ceria nanophosphors. Table 1 gives a comparison of the main parameters between the plasma-electrochemical technical and other conventional methods to show their pros and cons. Compared to the existing methods, it is indicated that this plasma-electrochemical method is relatively simpler. High purity $\mathrm{CeO}_{2}: \mathrm{Eu}^{3+}$ nanophosphors can be fabricated via a two-step manner: plasma electrodeposition reactions followed by a calcination process. Time and energy consuming pre/post-treatment procedures such as milling, pre-heating or organic washing are not needed. Moreover, this approach avoids the usage of any toxic chemicals, making it of great promising and interest to various applications, especially for the life science field.

\section{Conclusions}

In the present study, we have successfully synthesized europium doped ceria nanophosphors by a plasmaelectrochemical method, without the use of any toxic chemicals as well as complex purification procedures. Complementary characterizations were carried out to study the plasma-liquid interaction process as well as the obtained products. Results showed high purity crystalline $\mathrm{CeO}_{2}: \mathrm{Eu}^{3+}$ nanoparticles of the cubic fluorite structure were obtained, with an averaged crystallite size being calculated to be $52.2 \mathrm{~nm}$ at the calcination temperature of $1000^{\circ} \mathrm{C}$. Moreover, europium ions were proved to be effectively incorporated into the $\mathrm{CeO}_{2}$ matrix. The obtained nanophosphors exhibited clear downshifting behaviour, where the ${ }^{5} \mathrm{D}_{0} \rightarrow{ }^{7} \mathrm{~F}_{1}$ transition was found to be higher than the $\mathrm{D}_{0} \rightarrow{ }^{7} \mathrm{~F}_{2}$ transitions.

The combination of highly reactive plasma species, non-equilibrium state, milli-scale reactor and low-temperature operation may offer alternative routes for thermodynamically unfavorable reactions to take place under mild conditions. In terms of nanofabrication, plasma-based synthesis allows the production of nanostructures more efficiently in a well-controlled and green way. The unique kinetics of nonthermal plasma can lead to a fast nucleation but a slow crystal growth, in comparison to the traditional wet chemistry methods. Moreover, due to the high flexibility in choosing precursors, this method can produce a broad range of nanomaterials, such as metal nanoparticles, oxides, nitrides, nanoalloys as well as core/shell nanostructures. With the significant progress being achieved in the plasma-electrochemical nanofabrication field, it can be expected that this technique should have great potential

Table 1 Summary of main parameters for the synthesis of $\mathrm{CeO}_{2}$ :Eu nanoparticles by various methods

\begin{tabular}{|c|c|c|c|c|c|c|c|}
\hline Methods & Step & Extra toxic chemicals & Temperature $/{ }^{\circ} \mathrm{C}$ & Size/nm & Pre/post treatment & Remark & Ref. \\
\hline Plasma-assisted & 2 & None & $400-1000$ & $20-60$ & Centrifugation & $\begin{array}{l}\mathrm{Eu}_{2} \mathrm{O}_{3} \text { as the } \\
\text { raw material }\end{array}$ & [29] \\
\hline $\begin{array}{l}\text { Coprecipitation- } \\
\text { calcination }\end{array}$ & 4 & $\begin{array}{c}\mathrm{HNO}_{3} \\
\mathrm{NH}_{4} \mathrm{OH} \\
\mathrm{C}_{2} \mathrm{H}_{5} \mathrm{OH}\end{array}$ & 1300 & Micro-powder & $\begin{array}{c}\text { Centrifugation } \\
\text { Washing }\end{array}$ & & \\
\hline $\begin{array}{l}\text { Hydrothermal } \\
\text { method }\end{array}$ & 4 & $\begin{array}{c}\mathrm{Na}_{3} \mathrm{PO}_{4} \cdot 12 \mathrm{H}_{2} \mathrm{O} \\
\mathrm{C}_{2} \mathrm{H}_{5} \mathrm{OH}\end{array}$ & $180-450$ & $300-400$ & $\begin{array}{c}\text { Stirring } \\
\text { Centrifugation } \\
\text { Washing }\end{array}$ & & [23] \\
\hline $\begin{array}{l}\text { Ultrasonic spray } \\
\text { pyrolysis }\end{array}$ & 5 & $\begin{array}{c}\mathrm{C}_{2} \mathrm{H}_{6} \mathrm{O}_{2} \\
\mathrm{NaHCO}_{3} \\
\mathrm{HNO}_{3}\end{array}$ & 1000 & $40-80$ & $\begin{array}{l}\text { Dissolution } \\
\text { Centrifugation } \\
\text { Washing } \\
\text { Filtering }\end{array}$ & $\begin{array}{l}\text { Need to pre- } \\
\text { pare solution } \\
\text { droplets }\end{array}$ & [30] \\
\hline $\begin{array}{l}\text { Micro-emulsion } \\
\text { reaction method }\end{array}$ & 6 & $\begin{array}{c}\mathrm{C}_{6} \mathrm{H}_{8} \mathrm{O}_{7} \\
\mathrm{C}_{12} \mathrm{H}_{26} \mathrm{O}_{7} \\
\mathrm{C}_{6} \mathrm{H}_{14} \\
\mathrm{CHCl}_{3} \\
\mathrm{NH}_{4} \mathrm{OH}\end{array}$ & 1000 & $\begin{array}{c}30-55 \text { (surfactant } \\
\text { needed) }\end{array}$ & $\begin{array}{c}\text { Milling } \\
\text { Washing } \\
\text { Stirring } \\
\text { Evaporation }\end{array}$ & $\begin{array}{l}\mathrm{CeO}_{2} \text { as the } \\
\text { raw material }\end{array}$ & [31] \\
\hline Sol-gel method & 4 & $\begin{array}{l}\mathrm{C}_{6} \mathrm{H}_{8} \mathrm{O}_{7} \cdot \mathrm{H}_{2} \mathrm{O} \\
\text { Ethylene glycol }\end{array}$ & $400-900$ & $15-55$ & $\begin{array}{l}\text { Milling } \\
\text { Pre-fire } \\
\text { Stirring }\end{array}$ & $\begin{array}{l}\text { Complex } \\
\text { procedures }\end{array}$ & [32] \\
\hline Solvothermal process & 3 & $\begin{array}{l}\mathrm{C}_{2} \mathrm{H}_{5} \mathrm{OH} \\
\mathrm{NH}_{4} \mathrm{OH}\end{array}$ & $500-900$ & $5-27$ & $\begin{array}{c}\text { Pre-heating } \\
\text { Stirring } \\
\text { Washing } \\
\text { Centrifugation }\end{array}$ & $\begin{array}{l}\text { Long reaction } \\
\text { time }\end{array}$ & [33] \\
\hline
\end{tabular}


for the production of nanophosphors in a simple, flexible and environmentally friendly manner.

\begin{abstract}
Acknowledgements The authors would like to thank Ingeborg Schreur, Paul Bomans, Stefen C. J. Meskers, Tiny Verhoeven and Marco Hendrix from the Materials and Interface Chemistry Section and the Physical Chemistry Section, Eindhoven University of Technology, for technical assistance and helpful discussions. The authors also greatly acknowledge the funding support from Chinese Scholarship Council (CSC).
\end{abstract}

Open Access This article is licensed under a Creative Commons Attribution 4.0 International License, which permits use, sharing, adaptation, distribution and reproduction in any medium or format, as long as you give appropriate credit to the original author(s) and the source, provide a link to the Creative Commons licence, and indicate if changes were made. The images or other third party material in this article are included in the article's Creative Commons licence, unless indicated otherwise in a credit line to the material. If material is not included in the article's Creative Commons licence and your intended use is not permitted by statutory regulation or exceeds the permitted use, you will need to obtain permission directly from the copyright holder. To view a copy of this licence, visit http:// creativecommons.org/licenses/by/4.0/.

\section{References}

1. Dahle J T, Arai Y. Environmental geochemistry of cerium: Applications and toxicology of cerium oxide nanoparticles. International Journal of Environmental Research and Public Health, 2015, 12(2): 1253-1278

2. Younis A, Chu D, Li S. Cerium oxide nanostructures and their applications. Functionalized Nanomaterials, InTech, 2016, 10641324

3. Nikolaou K. Emissions reduction of high and low polluting new technology vehicles equipped with a $\mathrm{CeO}_{2}$ catalytic System. Science of the Total Environment, 1999, 235(1-3): 71-76

4. Brunner T J, Wick P, Manser P, Spohn P, Grass R, Limbach L K, Bruinink A, Stark W J. In vitro cytotoxicity of oxide nanoparticles: Comparison to asbestos, silica, and the effect of particle solubility. Environmental Science \& Technology, 2006, 40(14): 4374-4381

5. Celardo I, Pedersen J Z, Traversa E, Ghibelli L. Pharmacological potential of cerium oxide nanoparticles. Nanoscale, 2011, 3(4): 1411-1420

6. Vimal G, Mani K P, Biju P R, Joseph C, Unnikrishnan N V, Ittyachen $\mathrm{M}$ A. Structural studies and luminescence properties of $\mathrm{CeO}_{2}: \mathrm{Eu}^{3+}$ nanophosphors synthesized by oxalate precursor method. Applied Nanoscience, 2015, 5(7): 837-846

7. Kumar A, Babu S, Karakoti A S, Schulte A, Seal S. Luminescence properties of europium-doped cerium oxide nanoparticles: Role of vacancy and oxidation states. Langmuir, 2009, 25(18): 1099811007

8. Lin L, Wang Q. Microplasma: A new generation of technology for functional nanomaterial synthesis. Plasma Chemistry and Plasma Processing, 2015, 35(6): 925-962

9. Wang Z, Zhang Y, Neyts E C, Cao X, Zhang X, Jang B W L, Liu C J. Catalyst preparation with plasmas: How does it work? ACS Catalysis, 2018, 8(3): 2093-2110

10. Chen Q, Li J S, Li Y F. A review of plasma-liquid interactions for nanomaterial synthesis. Journal of Physics. D, Applied Physics,
2015, 48(42): 424005

11. Mariotti D, Patel J, Svrcek V, Maguire P. Plasma-liquid interactions at atmospheric pressure for nanomaterials synthesis and surface engineering. Plasma Processes and Polymers, 2012, 9(11-12): 1074-1085

12. Bruggeman P J, Kushner M J, Locke B R, Gardeniers J G E, Graham W G, Graves D B, Hofman-Caris R C H M, Maric D, Reid J P, Ceriani E, et al. Plasma-liquid interactions: A review and roadmap. Plasma Sources Science \& Technology, 2016, 25(5): 53002

13. Lin L, Starostin S A, Li S, Khan S A, Hessel V. Synthesis of yttrium oxide nanoparticles via a facile microplasma-assisted process. Chemical Engineering Science, 2018, 178: 157-166

14. Lin L, Starostin S A, Wang Q, Hessel V. An atmospheric pressure microplasma process for continuous synthesis of titanium nitride nanoparticles. Chemical Engineering Journal, 2017, 321: 447-457

15. Lee H, Park S H, Jung S C, Yun J J, Kim S J, Kim D H. Preparation of nonaggregated silver nanoparticles by the liquid phase plasma reduction method. Journal of Materials Research, 2013, 28(8): $1105-1110$

16. Hu C, Zhang Z, Liu H, Gao P, Wang Z L. Direct synthesis and structure characterization of ultrafine $\mathrm{CeO}_{2}$ nanoparticles. Nanotechnology, 2006, 17(24): 5983-5987

17. Shi S, Hossu M, Hall R, Chen W. Solution combustion synthesis, photoluminescence and X-ray luminescence of Eu-doped nanoceria $\mathrm{CeO}_{2}$ :Eu. Journal of Materials Chemistry, 2012, 22(44): 2346123467

18. Lin L, Li S, Hessel V, Starostin S A, Lavrijsen R, Zhang W. Synthesis of Ni nanoparticles with controllable magnetic properties by atmospheric pressure microplasma assisted process. AIChE Journal. American Institute of Chemical Engineers, 2018, 64(5): $1540-1549$

19. Ye B, Miao J L, Li J L, Zhao Z C, Chang Z, Serra C A. Fabrication of size-controlled $\mathrm{CeO}_{2}$ microparticles by a microfluidic sol-gel process as an analog preparation of ceramic nuclear fuel particles. Journal of Nuclear Science and Technology, 2013, 50(8): 774-780

20. Li Y X, Chen W F, Zhou X Z, Gu Z Y, Chen C M. Synthesis of $\mathrm{CeO}_{2}$ nanoparticles by mechanochemical processing and the inhibiting action of $\mathrm{NaCl}$ on particle agglomeration. Materials Letters, 2005, 59(1): 48-52

21. Schilling C, Hofmann A, Hess C, Ganduglia-Pirovano M V. Raman spectra of polycrystalline $\mathrm{CeO}_{2}$ : A density functional theory study. Journal of Physical Chemistry C, 2017, 121(38): 20834-20849

22. Zhang K, Pradhan A K, Loutts G B, Roy U N, Cui Y, Burger A. Enhanced luminescence and size effects of $\mathrm{Y}_{2} \mathrm{O}_{3}: \mathrm{Eu}^{3+}$ nanoparticles and ceramics revealed by $\mathrm{x}$-rays and raman scattering. Journal of the Optical Society of America. B, Optical Physics, 2004, 21(10): 1804-1808

23. Roh J, Hwang S H, Jang J. Dual-functional $\mathrm{CeO}_{2}: \mathrm{Eu}^{3+}$ nanocrystals for performance-enhanced dye-sensitized solar cells. ACS Applied Materials \& Interfaces, 2014, 6(22): 19825-19832

24. Václavů M, Matolínová I, Mysliveček J, Fiala R, Matolín V. Anode material for hydrogen polymer membrane fuel cell: $\mathrm{Pt}-\mathrm{CeO}_{2} \mathrm{RF}-$ sputtered thin films. Journal of the Electrochemical Society, 2009, 156(8): B938

25. Rajendran S, Khan M M, Gracia F, Qin J, Gupta V K, Arumainathan S. $\mathrm{Ce}^{3+}$-ion-induced visible-light photocatalytic degradation and 
electrochemical activity of $\mathrm{ZnO} / \mathrm{CeO}_{2}$ nanocomposite. Scientific Reports, 2016, 6(1): 31641

26. Yuan G, Li M, Yu M, Tian C, Wang G, Fu H. In situ synthesis, enhanced luminescence and application in dye sensitized solar cells of $\mathrm{Y}_{2} \mathrm{O}_{3} / \mathrm{Y}_{2} \mathrm{O}_{2} \mathrm{~S}: \mathrm{Eu}^{3+}$ nanocomposites by reduction of $\mathrm{Y}_{2} \mathrm{O}_{3}: \mathrm{Eu}^{3+}$. Scientific Reports, 2016, 6(1): 37133

27. Kumar S, Kumar A. Enhanced photocatalytic activity of rGO-CeO nanocomposites driven by sunlight. Materials Science \& Engineering B. Solid-State Materials for Advanced Technology, 2017, 223 : 98-108

28. Sun C W, Li H, Zhang H R, Wang Z X, Chen L Q. Controlled synthesis of $\mathrm{CeO}_{2}$ nanorods by a solvothermal method. Nanotechnology, 2005, 16(9): 1454-1463

29. Zhang J, Ke C, Wu H, Yu J, Wang J, Wang Y. Solubility limits, crystal structure and lattice thermal expansion of $\mathrm{Ln}_{2} \mathrm{O}_{3}(\mathrm{Ln}=\mathrm{Sm}$, $\mathrm{Eu}, \mathrm{Gd}$ ) doped $\mathrm{CeO}_{2}$. Journal of Alloys and Compounds, 2017, 718 : 85-91
30. Min B H, Lee J C, Jung K Y, Kim D S, Choi B K, Kang W J. An aerosol synthesized $\mathrm{CeO}_{2}: \mathrm{Eu}^{3+} / \mathrm{Na}^{+}$red nanophosphor with enhanced photoluminescence. RSC Advances, 2016, 6(84): 81203-81210

31. Avram D, Rotaru C, Cojocaru B, Sanchez-Dominiguez M, Florea M, Tiseanu C. Heavily impregnated ceria nanoparticles with europium oxide: Spectroscopic evidences for homogenous solid solutions and intrinsic structure of $\mathrm{Eu}^{3+}$-oxygen environments. Journal of Materials Science, 2014, 49(5): 2117-2126

32. Li L, Yang H K, Moon B K, Fu Z, Guo C, Jeong J H, Yi S S, Jang K, Lee H S. Photoluminescence properties of $\mathrm{CeO}_{2}: \mathrm{Eu}^{3+}$ nanoparticles synthesized by a sol-gel method. Journal of Physical Chemistry C, 2009, 113(2): 610-617

33. Thorat A V, Ghoshal T, Carolan P, Holmes J D, Morris M A. Defect chemistry and vacancy concentration of luminescent europium doped ceria nanoparticles by the solvothermal method. Journal of Physical Chemistry C, 2014, 118(20): 10700-10710 